\title{
Web Application for the Management of Projects of the Division of Postgraduate Studies and Research of the Technological Institute of Oaxaca
}

\section{Aplicación web para la Gestión de proyectos de la División de Estudios de Posgrado e Investigación del Instituto Tecnológico de Oaxaca}

\author{
RAFAEL-PÉREZ, Eva†*, CHÁVEZ-CRUZ, Dagoberto, LUJÁN-LUGOS, Héctor Ángel and \\ SÁNCHEZ- MEDINA, Marco Antonio
}

Tecnológico Nacional de México/Instituto Tecnológico de Oaxaca, Avenida Ing. Víctor Bravo Ahuja No. 125 Esquina Calzada Tecnológico, Oaxaca, Oax., México. C.P. 68030

ID $1^{\text {st }}$ Author: Eva, Rafael-Pérez / ORC ID: 0000-0003-2793-1254, CVU CONACYT ID: 905268

ID $1^{\text {st }}$ Co-author: Dagoberto Chávez Cruz / ORC ID: 0000-0002-1067-1954, CVU CONACYT ID: 1148202

ID $2^{\text {nd }}$ Co-author: Héctor Ángel Lujan Lugos / ORC ID: 0000-0003-1536-1872, CVU CONACYT ID: 1148158

ID $3^{\text {rd }}$ Co-author: Marco Antonio Sánchez Medina / ORC ID: 0000-0002-1411-5955, CVU CONACYT ID: 50313

DOI: $10.35429 /$ JCSI.2021.19.7.21.29

Received July 25, 2021; Accepted October 20, 2021

\begin{abstract}
In accordance with the calls for proposals for technological development and innovation and scientific research projects, issued by the National Technological Institute of Mexico (TecNM), each campus belonging to the TecNM must carry out the management of the projects that are authorized in each period in order to have timely information on the status of each project in terms of progress, application of resources, goals achieved, etc. Based on these needs in the Technological Institute of Oaxaca, specifically in the Coordination of the Division of Postgraduate Studies and Research, the need to have a web tool that supports said project management becomes clear. The objective of this web tool is precisely the management, control and monitoring of the stages, advances, items and sub-items of the research project financing, based on the periods established by the TecNM, maintaining effective communication between the institutional coordinator and the project leader through notifications. The agile extreme programming model, JavaScript and the Express framework were used in the development of the software.
\end{abstract}

Web application, Research project, Management

\begin{abstract}
Resumen
De acuerdo con las convocatorias de propuestas de proyectos de desarrollo tecnológico e innovación y de investigación científica, emitidas por el Tecnológico Nacional de México (TecNM), en cada Instituto perteneciente al TecNM se debe realizar la gestión de los proyectos que se autorizan en cada periodo con el fin de contar con información puntual sobre el estado que guarda la investigación en cuanto a avance, aplicación de recursos, metas alcanzadas, etc. A partir de estas necesidades en el Instituto Tecnológico de Oaxaca, específicamente en la Coordinación de Investigación de la División de Estudios de Posgrado e Investigación (DEPI), se hace patente la necesidad de contar con una herramienta web que apoye dicha gestión de proyectos. El objetivo de esta herramienta web es precisamente la gestión, control y seguimiento de las etapas, avances, partidas y subpartidas del financiamiento del proyecto de investigación, con base en los periodos establecidos por el TecNM, manteniendo la comunicación efectiva entre el coordinador institucional y el líder del proyecto a través de notificaciones. En el desarrollo del software se utilizó el modelo ágil de programación extrema, JavaScript y el Framework Express.
\end{abstract}

Aplicación web, Proyecto de investigación, Gestión

Citation: RAFAEL-PÉREZ, Eva, CHÁVEZ-CRUZ, Dagoberto, LUJÁN-LUGOS, Héctor Ángel and SÁNCHEZ- MEDINA, Marco Antonio. Web Application for the Management of Projects of the Division of Postgraduate Studies and Research of the Technological Institute of Oaxaca. Journal of Computational Systems and ICTs. 2021. 7-19: 21-29

\footnotetext{
* Author Correspondence (e-mail: evarafaelperez@gmail.com)

$\dagger$ Researcher contributing as first Author.
} 


\section{Introduction}

At the Instituto Tecnológico de Oaxaca, scientific and technological research is a key activity that allows teachers to actively generate projects in the search for real solutions and that through the DEPI makes possible the coordination and management of research projects that the TecNM finances through annual calls. The web application for project management arises from the need of the DEPI for internal control of research projects in the monitoring, progress and records of the project, items and sub-items of funding based on the periods established by the TecNM.

Once the funding has been approved and obtained by the TecNM, the internal process begins with the registration of the approved project, the funding data and the budget items and sub-items of the approved resource that through the use of the web tool, the Research Coordinator of the DEPI validates that the delivery of the partial reports are sent by the project leader in due time and form, the process is completed when the final report is delivered and the coordinator validates the process,

The application allows the follow-up of each of the advances and records of the project based on the established periods, maintaining the interaction between the leader and the coordinator through notifications, thus avoiding delays in the delivery of the protocol and the partial and final reports of the project, in addition to increasing the efficiency in the processes and the adequate control of the research projects.

The web application has a database using the MySQL database manager for the proper control of the records of each of the projects, funding, items, sub-items, users, thus avoiding the problems of lack of data integrity and a structure to store and organize the information, which allows efficient search processes, and that the information is available at any time.

The web tool intuitively displays graphical interfaces that allow users to navigate the application in a simpler and more userfriendly way for capturing, recording and sending information. The application displays a drop-down list of the items and sub-items corresponding to each of the financing items to prevent users from making erroneous choices, thus avoiding inconsistencies in the information.
Another important benefit of the system is that it allows users to download the information in PDF format for review or verification, thus reducing file transcription and/or search times. Therefore, the present work is composed of the following sections: problem statement, methodology, types of users, development, results, conclusions and references.

\section{Problem Statement}

The DEPI is in charge of managing the TecNM research projects that participate in the calls published each year, once the research project is approved and obtained the funding, the internal process is carried out manually and starts with the registration of the approved project data, the funding data and the budget items under which the use of the approved resource is governed, the data of the leaders and collaborators. Once the projects are registered, the research coordinator of the DEPI informs each project leader of the dates for the delivery of the partial and final reports via e-mail.

Another problem that arises is the leader's lack of knowledge of the items and subitems, since when they are assigned, they do not correspond to the corresponding items or subitems, and when the coordinator verifies, he notices that there is inconsistent information.

For the review and verification process of each project the coordinator has to download the file manually, as the file is in an image format and even if the information is correct or not, the project has to be transcribed to text, which causes workloads, drafting errors and loss of time. Once the project revisions and reports are sent by the leader, the DEPI research coordinator reviews the final report so that the project leader can upload the information to the TecNM platform; from this process a PDF file is obtained as the final product, this information is printed and filed physically, so that when the information is required or requested, the search has to be done manually or by file name, which causes loss of time. The following problems were identified: lack of control and an adequate structure for the storage of information, lack of data integrity, inconsistency in the information, lack of adequate follow-up and delays in the progress of the project, loss of time in the specific search for a project and time consumption in the transcription of information. 


\section{Methodology}

For the development of a software there are different methodologies to use, however not all of them are adapted to the particular needs of each case, for the Web Application for the project management of the DEPI of the Technological Institute of Oaxaca, the methodology of agile development in Extreme Programming (XP Extreme Programming) was used; proposed by Kent Beck in 1999, in his book "Extreme Programming Explaned"; which has as its main objective customer satisfaction and optimization of development time, this due to its characteristics, since it is an agile and flexible methodology, there is constant interaction between the customer and the development team, it works in pairs which allows peer review, which helps to quickly identify possible errors, reuses the code, carries out refactoring, which means improving the quality of the code and correcting problems, hence optimizing time. The stages are: analysis, design, coding and testing.

In this application we worked with three iterations, in addition two types of roles were identified as indispensable for its operation with their respective functions. The Administrator User is the DEPI's Research Coordinator, who has full access to the web application, which allows him/her to add and list participants and project funding, assign accounts to previously registered participants, list active and inactive accounts, register new items and sub-items for the breakdown of project expenses, perform searches by participant and by project, add and list previous projects to the application, add and list projects prior to the DEPI, add and list participants and project funding, assign accounts to previously registered participants, list active and inactive accounts, register new items and sub-items for the breakdown of project expenses, perform searches by participant and by project, add and list participants and by project, add and list projects prior to the creation of the system, visualize projects with colored traffic lights to identify their status, visualize the progress of projects, review research protocols, reports and project deliverables, add observations for each of the documents reviewed, visualize collaborators, the breakdown of project expenses, download project reports in different formats and mark projects as completed.
The Responsible user is the teacher leading the project, can add projects with a funding key created by the administrator, list the active projects that correspond to him/her, view the progress of the project, upload research protocol and reports, add and list project deliverables and add materials and services for the breakdown of the amount authorized for the project.

\section{Development}

The development of the web application was based on three iterations that were carried out according to the phases of the extreme programming methodology. In the Analysis phase, a meeting plan was made to define the tasks, the progress of the system and the review dates. For this activity, the interaction and communication with the external consultant was essential.

\begin{tabular}{|c|c|c|}
\hline $\begin{array}{l}\text { Meeting } \\
\text { No. }\end{array}$ & Activity & Date \\
\hline 1 & Define the master list of users & 021120 \\
\hline 2 & System requirements gathering & 091120 \\
\hline 3 & $\begin{array}{l}\text { proposal for the operation of the } \\
\text { system }\end{array}$ & 231120 \\
\hline 4 & $\begin{array}{l}\text { Review of the functionality of the } \\
\text { financing management, project } \\
\text { management, user management } \\
\text { and system access modules. }\end{array}$ & 071220 \\
\hline 5 & Delivery of the first iteration & 140120 \\
\hline 6 & $\begin{array}{l}\text { Review of line item and sub-item } \\
\text { modules, reports, upload } \\
\text { protocol, schedules, project } \\
\text { content and comments. }\end{array}$ & 180121 \\
\hline 7 & Delivery of the second iteration & 010221 \\
\hline 8 & $\begin{array}{l}\text { Revision of the Project Tracking, } \\
\text { Traffic Light, Repository, } \\
\text { Notifications and Password } \\
\text { Reset modules. } \\
\text { Repository, Notifications and } \\
\text { Password Reset. }\end{array}$ & 010321 \\
\hline 9 & Delivery of the third iteration & 200321 \\
\hline 10 & Delivery of the final project & 270321 \\
\hline
\end{tabular}

Table 1 Delivery meeting plan and progress Source: Own Elaboration

Table 2 shows the master list of iterations and the tasks that were defined for the development of the project. 


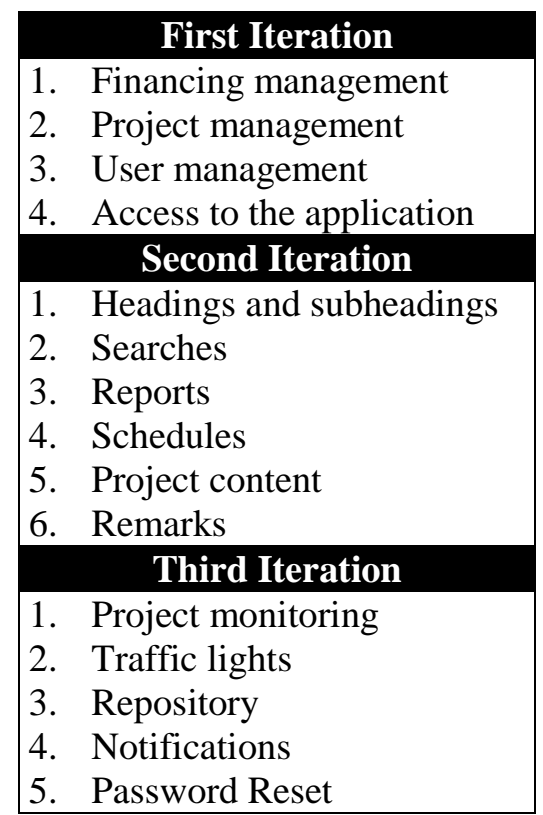

Table 2 Master list of the main iterations Source: Own Elaboration

For the definition of the functional and non-functional requirements, the user story technique was used, which can be applied in agile methods, they are a brief description of a software functionality as perceived by the user (Cohn, 2004); it is important to mention that different user stories were developed in each iteration.

Table 3 shows the fields that were considered most necessary to adequately describe the user story, such as:

- ID: 01; unique user story identifier for the functionality or job.

- $\quad$ Title: Add funding; descriptive title of the user story.

- Description: As an administrator user I want to add funding for research projects accepted by TecNM; synthesized description of the user story based on the pattern: As [user role], I want [objective], so that I can [benefit], according to Cohn (2004), as it ensures that the functionality is described at a high level and not too extensively.

- Validation criteria: acceptance tests agreed with the client or user, in this example the user's request is validated.

\begin{tabular}{|l|l|}
\hline \multicolumn{2}{|c|}{ User History } \\
\hline Número: 1 & Name: Add financing \\
\hline User: Administrator & Iteration assigned: 1 \\
\hline Priority: High & Estimated points: 2 \\
\hline Development risk: high & Description: \\
I as an administrator user, want to add funding for research \\
projects authorized by TecNM. \\
\hline Observations: \\
$-\quad$ Have a funding key given by TecNM. \\
$-\quad$ Add the financing start date. \\
$-\quad$ Have an expiration date, this date is automatically \\
generated with a period of one year. \\
- It must allow to add approved items and the authorized \\
amount for each one. \\
- It must allow to delete a line item. \\
- It must contain a Button that allows to add the financing \\
$\quad$ to add the key. \\
\hline
\end{tabular}

Table 3 User Story to add financing Source: Own Elaboration

In the design stage, the XP methodology makes special emphasis on simple and clear designs, one of the important aspects with which we worked on the design was Simplicity, meaning a simple design that works and can be implemented more quickly, in relation to the refactoring or recoding, we modified part of the code of some modules without changing its functionality, with the objective of a simpler, concise and understandable design.

For many types of software, design and construction are linked. That is, both activities must be executed simultaneously, so that the design models are tested as they are created according to Pressman S. Royer (2010), therefore; the design results depended on the iteration in which it was worked, for example in iteration one was obtained as a result the creation of the database through the relational database manager system based on Nevado, M. (2010).

The database management system used in this project is MySQL which is an open source relational database management system based on structured query language; it runs on virtually all platforms, including Linux, Unix and Windows. Although it can be used in a wide range of applications, it is most associated with web-based applications.

In the design of the interfaces, these were generated according to the iteration that was being designed considering the master list of iterations. 
In the coding phase we used the Express framework for web applications from the OpenJS foundation, it is open source and works with Node.js, it provides a thin layer of features for the creation of web applications, which allows it to be fast and minimalist, its main functions are the management of routes, integration with databases, template engine, error handling. It is a framework without opinions, which lets programmers work the way they want without forcing them to take a particular path, besides being easy to use.

The coding results were also a function of the iterations; in the first iteration the following modules were coded: financing, projects, users and access; for the second iteration the modules of items and sub-items, searches, development of schedules, reports, observations and project content were coded. Finally, in the third iteration, the modules for project tracking, project traffic lights, repository for historical projects, system notifications and password resetting were developed.

The web application was based on a client-server architecture, where the client (user) makes requests to the server (computer) and the server responds with the requested information, taking into account the needs of the end user and the advantages offered by the client-server scheme such as the use of different operating systems, graphical interfaces easy to understand for the user, modular structure that allows easy integration of new technologies, frequency and time of use of the application and data integrity, as shown in Figure 1.

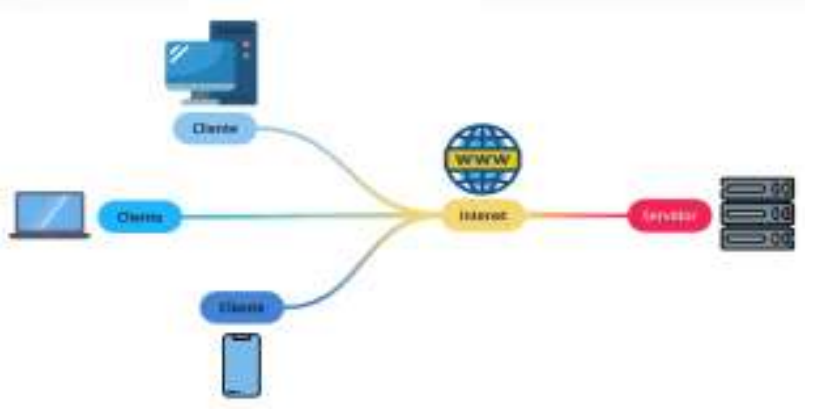

Figure 1 Client-server architecture design Source: Own Elaboration

The testing stage, for Somerville (2005) are the tests that are applied to demonstrate to the customer that the software meets their requirements, for the web application different tests were performed in each iteration, such as:
- $\quad$ The unit tests, which focuses on focusing on each module, the integration tests whose objective is to verify the correct assembly between the different components once they have been unit tested in order to verify that they interact correctly through their interfaces, cover the established functionality and adjust to the non-functional requirements.

Acceptance tests that aim to check if the software is ready and can be used by users to perform the functions and tasks for which it was designed, where the customer tests and verifies that it meets their expectations.

- $\quad$ The validation tests where it is verified that the application serves the purpose for which it was created, is a necessary programming task, to execute and verify that the inputs are of the correct type and that they are complete with data, since they facilitate the programming and improvement of the user interface and the satisfaction of the final user with the developed software.

The validation test process for the reports is described below.

A fundamental stage of the project are the reports, these have established time periods to be delivered and keep track of the exact stage and status in which they are.

In the user interface of the Responsible or project leader visualizes the date validations that have to be performed for the proper generation of reports, as it shows the number of days remaining for the Pdf upload option to be activated as shown in Figure 2.

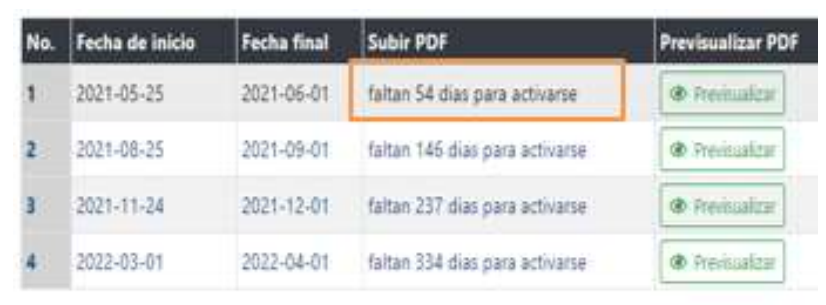

Figure 2 Validation of report dates

Source: Own Elaboration

The option is activated so that the project leader can upload his reports, and it will only remain active for one week, as shown in Figure 3.

RAFAEL-PÉREZ, Eva, CHÁVEZ-CRUZ, Dagoberto, LUJÁNLUGOS, Héctor Ángel and SÁNCHEZ- MEDINA, Marco Antonio. Web Application for the Management of Projects of the Division of Postgraduate Studies and Research of the Technological Institute of Oaxaca. Journal of Computational Systems and ICTs. 2021 


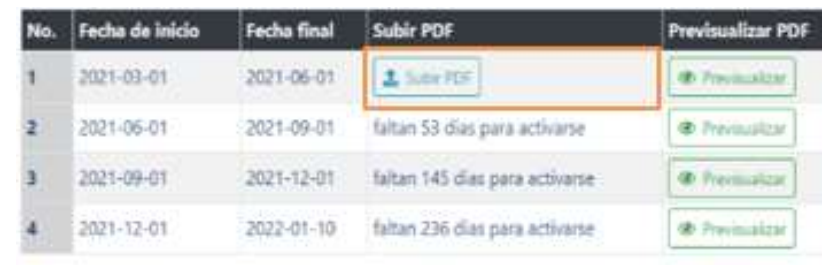

Figure 3 Active option to upload reports Source: Own Elaboration

Once the Upload report option is activated, it is validated, so that it is not sent without having uploaded or selected any file, in case of doing so, a message is displayed. In addition to this, the system validates that only files in PDF format can be uploaded, as shown in figure 4.

\section{Subir Informe}

Proyecto: Desarrollo de Sistema Web DEPI

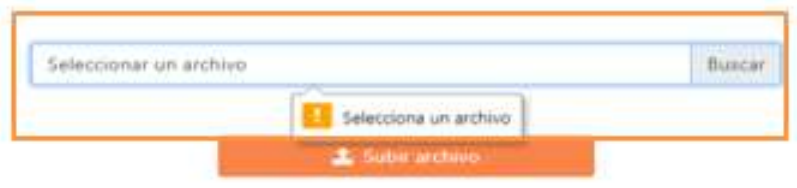

Figure 4 Validation of file in Pdf format Source: Own elaboration

\section{Results}

The web application for project management of the DEPI of the Instituto Tecnológico de Oaxaca allows the management, control and follow-up of the advances, items and sub-items of the research project financing, under the TecNM guidelines as well as the established periods.

Different modules were implemented for this application: system access module, participants, users, financing, projects, items and sub-items, searches, reports, project follow-up and traffic lights, historical projects and password reset. The following is a description of the important modules of the web application.

\section{- $\quad$ System access screen}

Shows the access to the Web Application, where only registered and authorized users can $\log$ in through a username and password. See Figure 5.

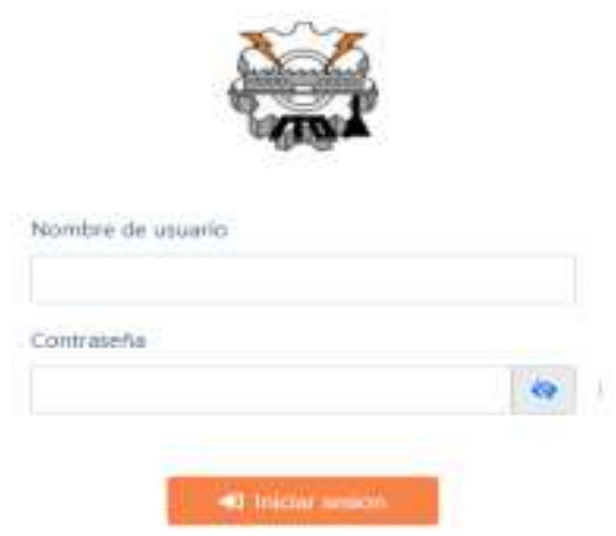

Figure 5 Access to the system Source: Own Elaboration

\section{- $\quad$ Main screen of the administrator}

The main screen of the application contains the following menu of options: Participants, Basins, Financing, Sub-items, Search, History, Projects, Notifications and the Exit option, see Figure 6.

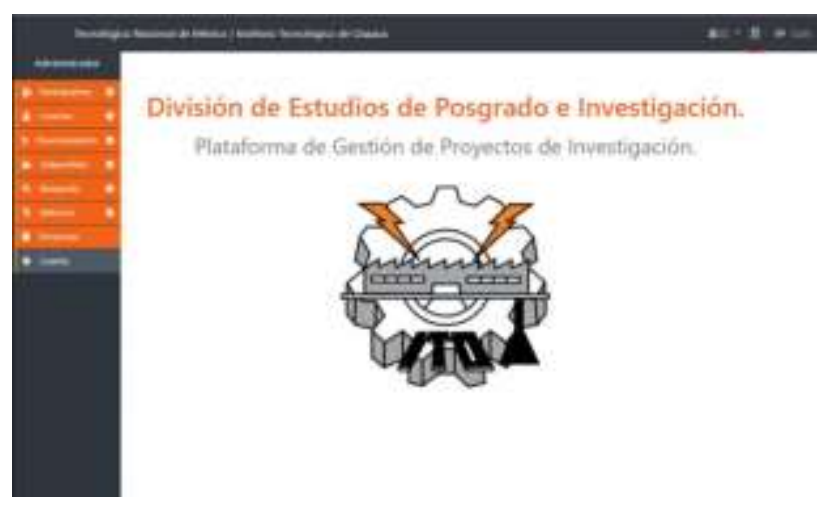

Figure 6 Main menú Source: Own Elaboration

- The Participant module allows registering the participants of the system through a unique identifier that corresponds to a CVU number (Unique Curriculum Vitae) that each participating teacher has registered with the TecNM, the data added are full name, the participant's campus of origin, an e-mail, the module has a Create Participant button that allows re-registering the participant, it also lists the previously registered participants, as shown in Figure 7. 


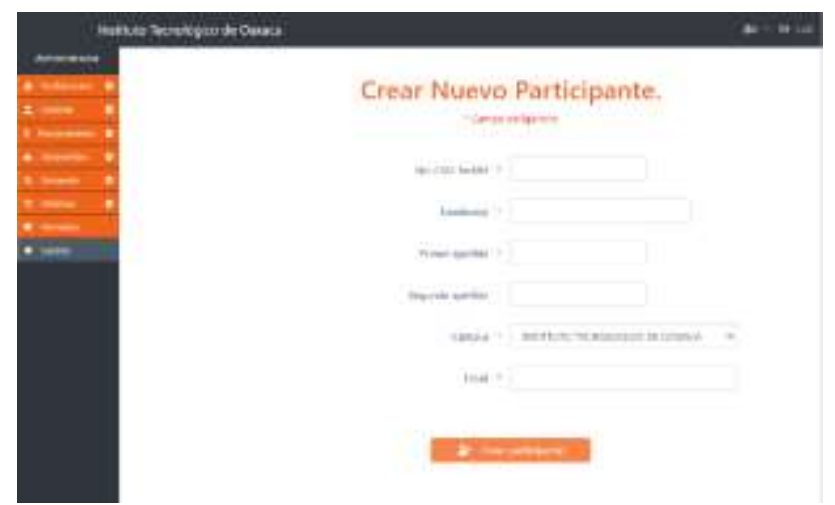

Figure 7. Main screen of the system Source: Own Elaboration

- Accounts Module. Allows the creation of access accounts for previously registered participants. A member is selected, the e-mail address is automatically filled in, a random and secure password is generated, a role is added, and a Register button is used to create the participant's access account. See figure 8.

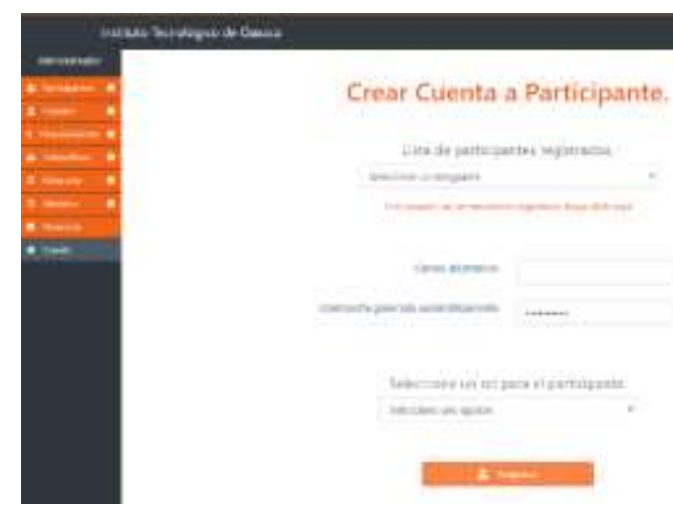

Figure 8 Participant's account Source: Own elaboration

- Funding module, this module adds funding through a key that is assigned to the research project when it is authorized by the TecNM, the start date of the funding is specified and the expiration date is automatically generated, the approved items and the authorized amount for each project are added. See figure 9.

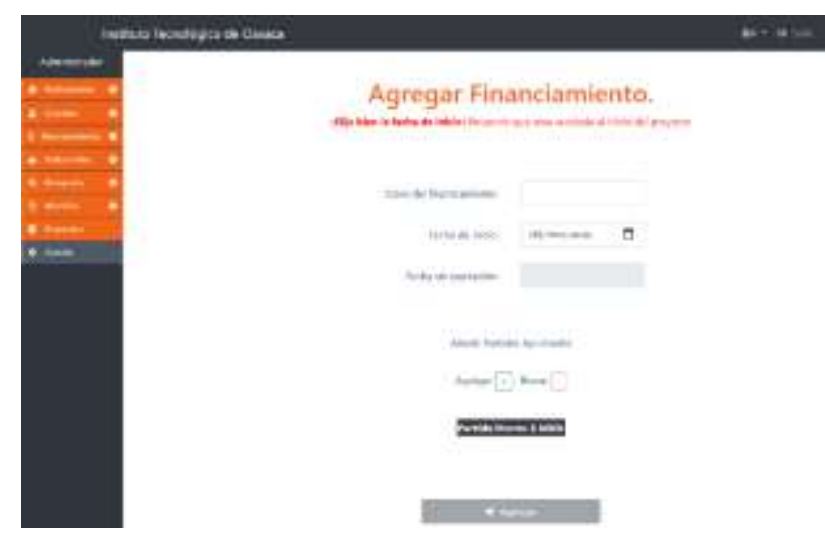

Figure 9 Add Financing Source: Own Elaboration
- Sub-items module, allows the creation of new authorized items and sub*-items to break down project expenditures by means of an item key, a description can be added and deleted to justify how the money under that sub-item will be broken down, as shown in Figure 10.

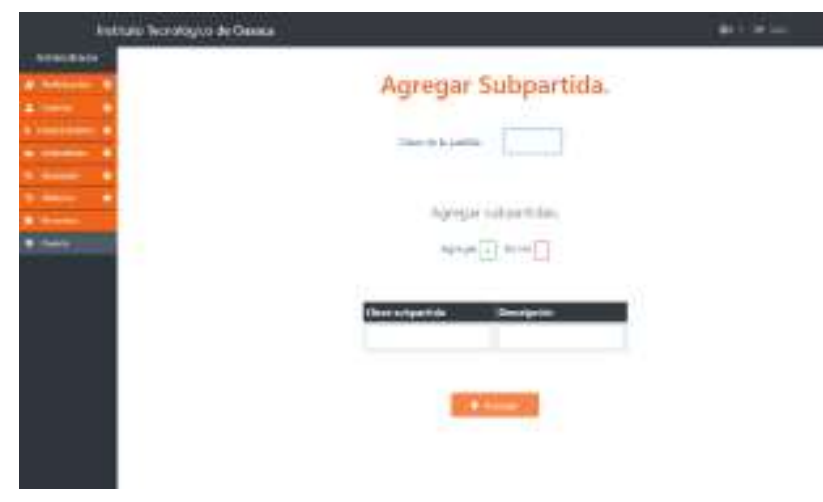

Figure 10. Adding a subheading Source: Own Elaboration

Figure 11 shows a glossary of subheadings authorized by the TecNM for the breakdown of project expenses.

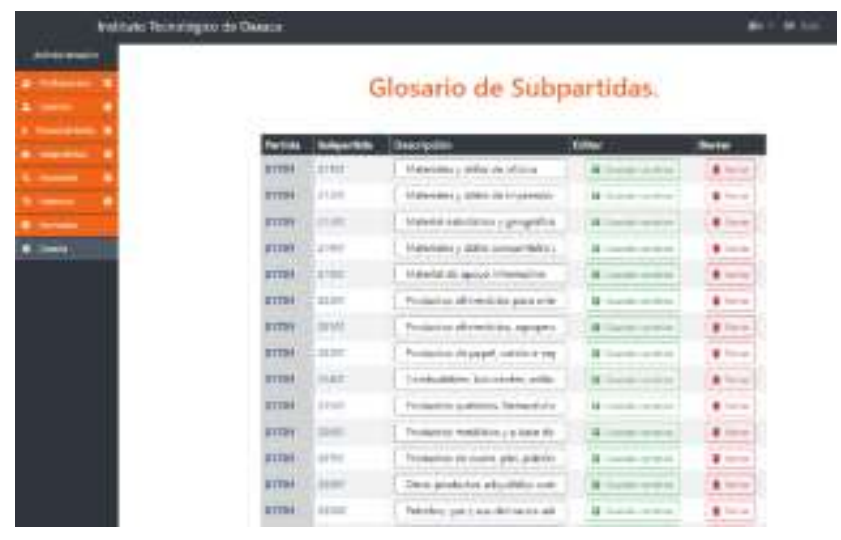

Figure 11 Glossary of subheadings Source: Own Elaboration

Projects module, this module is one of the most important of the web application, since it allows the management and monitoring of projects, it shows the visualization of research projects through a colored traffic light with project statuses, it can be filtered according to their status and visualize their individual details.

This module shows the project statuses: On Time means that all projects are on time and on track, Overdue: all projects that are Overdue are displayed. The Finished status shows all the projects that are Finished and also all the projects that are Cancelled, as shown in Figure 12. 


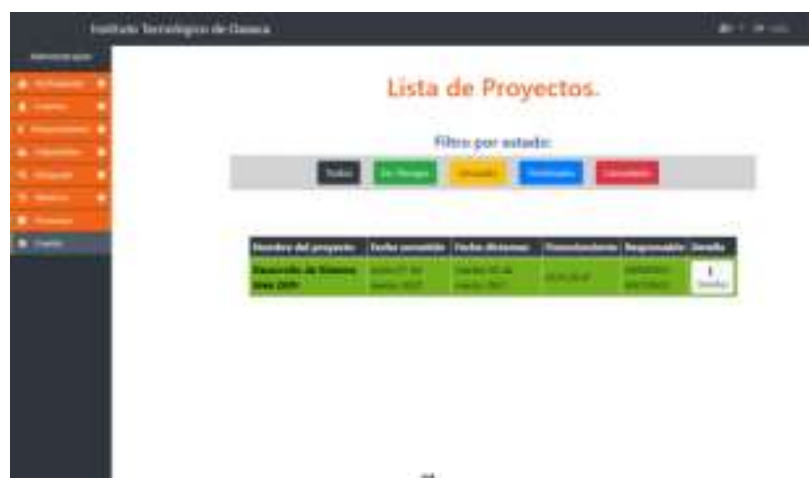

Figure 12 List of projects Source: Own Elaboration

Figure 13 shows the Project Details, it is the main view of each project, it allows to observe the progress over time and the side menu changes adjusting to the project details as described below:

- Progress: allows to go back to view the progress of the project.

- Protocol: Allows to view the research protocol of the project.

- Reports: Allows to view the partial and final reports of the research project.

- Deliverables: Allows to view the deliverables recorded by the project leader.

- Expenses: Allows to view the breakdown of the project expenses.

- Collaborators: Allows to view the participants that were registered as collaborators by the project leader.

- It has the option to return to the previous menu.

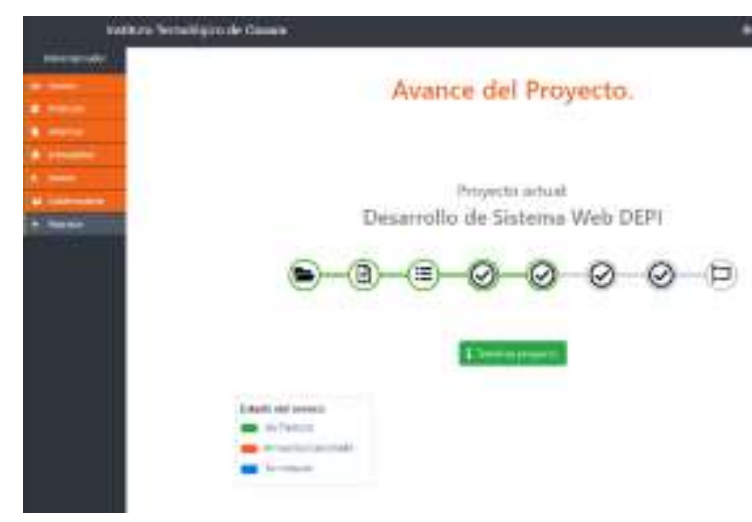

Figure 13 Project progress

Source: Own Elaboration

\section{Acknowledgments}

To the Tecnológico Nacional de México/Instituto Tecnológico de Oaxaca for the facilities and spaces for the development of this research work.
We are grateful for the collaboration and dedication of the authors of the article, professors and students who participated with responsibility in the research until the achievement of the results presented; the objective of this research is to disseminate the findings to the academic community and the general public about the work being developed at the Institution.

\section{Conclusions}

The use of web technologies for the development and implementation of the web application for the management of research projects brings to the DEPI the internal control of the projects that the teachers of the Instituto Tecnológico de Oaxaca generate actively in the search for real solutions under the guidelines of the Tecnológico Nacional de México based on the calls issued each year.

One of the benefits of the web application is the control and follow-up of the research projects, which through the colored traffic lights the research coordinator of the DEPI knows the status of the project; in the same way it allows the interaction with the project leader to add the corresponding information of the project, since the system allows the coordinator to make the necessary feedback of the project so that it can be attended by the leader without any confusion or delays in the delivery.

In relation to the project leader, the application allows him to add a project, assign the items and sub-items appropriately and the amount authorized for the development of the research and know the materials and services in which it was spent; in addition to sending the protocol and reports in a timely manner. The web application has a database to store the information of the projects, items, sub-items, amount, users, accounts, participants, protocol and reports, which allows to have a history of the reports made during the year of validity.

The development of the web application greatly benefits the Coordinator and the teachers, since it has an efficient control of the research projects, each participant leader knows in a timely manner in which part of the process is, since the system keeps track of each process, and is notified about delivery times of the documents thus avoiding delays in deliveries, in addition to the projects can be canceled for noncompliance or long waiting times.

RAFAEL-PÉREZ, Eva, CHÁVEZ-CRUZ, Dagoberto, LUJÁNLUGOS, Héctor Ángel and SÁNCHEZ- MEDINA, Marco Antonio. Web Application for the Management of Projects of the Division of Postgraduate Studies and Research of the Technological Institute of Oaxaca. Journal of Computational Systems and ICTs. 2021 
In general, the system provides several benefits, one of them is that at the moment of carrying out each internal process through the web application, the user is notified in a timely manner about any event or requirement of the project being carried out; the internal control of the process of research projects becomes more efficient, the attention provided to leading teachers improves by reducing waiting times and avoiding unnecessary constant visits since it can be consulted directly in the web application from any place with Internet access, having the information available in time and form; processed and stored information that helps in decision making.

\section{References}

Cobo, Á., Gómez, P., Pérez, D., \& Rocha, R. (2005). PHP y MySQL Tecnologías para el desarrollo de aplicaciones web. Ediciones Díaz Santos

Cohn, M. (2004). User Stories Applied for Agile Software Development. Boston: Pearson Education, Inc.

De miguel Adoración., Piattini Mario., Marcos Esperanza. (2000). Diseño de base de datos relacionales. Alfaomega

Eguíluz Pérez Javier. (Junio de 2008). Introducción a JavaScript. https://goo.gl/y0cWEG

Ibáñez, L. H., Cabrera, J. L. R., Galindo, L. H. I., y Tome, A. G. (2011). Administración de sistemas gestores de bases de datos: grado superior. Alianza Editorial.

Kendall, J. E. (2005). Análisis y diseño de sistemas. Pearson Educación.

Lafosse, J. (s.f.). Struts 2: El framework de desarrollo de aplicaciones Java EE 2014. Cornellà de Llobregat (Barcelona): ENI.

Laudon, K., y Laudon, J. (2004). Sistemas de información gerencial. Octava edición. México: Pearson

Lineamientos para el Desarrollo de la investigación en el Tecnológico Nacional de México. D.R. (C) Tecnológico Nacional de México. Noviembre 2018
Luján Mora Sergio. Programación de aplicaciones web: historia, principios básicos y clientes web. Editorial Club Universitario, Alicante, 2002. ISBN: 978-84-8454-2063. (PI'2002) Libro / Book

Nevado, M. (2010). Introducción a Las Bases de Datos Relacionales. España: Visión Libros

Pressman, R., \& Murrieta, J. (2006). Ingeniería del software un enfoque práctico $\left(6^{\mathrm{a}}\right.$ Edición ed.). McGraw-Hill.

Sommerville, Ian M. I. (2005). Ingeniería del software. Pearson Educación.

Schulz, R. (2021). Diseño Web Con Css. Alfa omega Grupo Editor.

Zaefferer Jörn. (s.f). Validación de formularios con jQuery. https://Jqueryvali-dation.org/ 